\title{
BMJ Open Can the 'Learn in peace, educate without violence' intervention in Cote d'Ivoire reduce teacher violence? Development of a theory of change and formative evaluation results
}

To cite: Devries K, Balliet M, Thornhill $\mathrm{K}$, et al. Can the 'Learn in peace, educate without violence' intervention in Cote d'Ivoire reduce teacher violence? Development of a theory of change and formative evaluation results. BMJ Open 2021;11:e044645. doi:10.1136/ bmjopen-2020-044645

- Prepublication history for this paper is available online. To view these files, please visit the journal online (http://dx.doi. org/10.1136/bmjopen-2020044645).

Received 24 September 2020 Accepted 05 October 2021

Check for updates

(c) Author(s) (or their employer(s)) 2021. Re-use permitted under CC BY-NC. No commercial re-use. See rights and permissions. Published by BMJ.

For numbered affiliations see end of article.

Correspondence to

Dr Karen Devries;

karen.devries@Ishtm.ac.uk

\section{ABSTRACT}

Objectives To gather evidence on whether a brief intervention (Apprendre en paix et éduquer sans violence, developed by the Ivorian Ministry of Education and Graines de Paix) to promote peace in primary schools by reducing teacher violence perpetration and improving pedagogical techniques was acceptable to teachers and affected change in intermediate outcomes.

Design Mixed-methods formative research.

Setting Primary schools in Tonkpi region, Cote d'Ivoire. Participants 160 teachers participating in the peace training, surveyed three times during implementation; qualitative in-depth interviews with 19 teachers and teacher-counsellors.

Interventions Learn in peace, educate without violence-a brief intervention with primary school teachers designed to promote peace in primary schools.

Outcomes For survey data, we generated composite measures of intermediate outcomes (teachers' awareness of consequences of violence, self-efficacy in applying positive classroom management methods, acceptance of physical discipline practices in school) and used random intercept linear mixed-effects models to compare responses over time. Qualitative research included open-ended questions about acceptability and perceived need for such an intervention. A framework analysis was undertaken.

Results Four-months post-training (vs pretraining), teachers had higher self-efficacy in applying positive classroom management methods (pre-mean $=26.1$; post-mean $=27.5 ; p<0.001$ ) and borderline lower acceptance of physical discipline practices (premean $=4.2$; postmean $=3.6 ; p=0.10$ ). We found no change in teacher awareness of the consequences of violence. Qualitatively, teachers found the intervention acceptable and understandable, perceiving it as useful because it provided methods for non-violent discipline. Teachers had mixed views about whether the techniques improved classroom dynamics.
Strengths and limitations of this study

- We explored whether Apprendre en paix et éduquer sans violence (APEV), an non-governmental organisation (NGO)-developed brief intervention to reduce teacher's use of physical violence against students, was acceptable and associated with changes in intermediate outcomes in teachers in Cote d'Ivoire.

- We outlined a Theory of Change for the APEV at a workshop, which included intervention developers and stakeholders.

- We used both qualitative and quantitative methods to address intermediate outcomes identified in the Theory of Change.

- Further investigation of this brief intervention to explore its effectiveness in reducing violence is warranted.

Conclusions Data suggest that the intervention is acceptable and leads to change in intermediate outcomes for teachers. Further evaluation in a randomised controlled trial is warranted.

\section{INTRODUCTION}

Globally, more than $50 \%$ of children report experiencing physical, sexual or emotional violence in the past year. ${ }^{1}$ One common, but understudied perpetrator of violence in childhood is teachers. ${ }^{2}$ Health effects of physical violence experienced in childhood include increased risk of future sexually transmitted infections, ${ }^{3}$ poor mental health ${ }^{3}$ as well as poor educational ${ }^{4}$ and employment outcomes. ${ }^{5}$

In conflict-affected contexts such as Côte d'Ivoire, school-based interventions to reduce violence may be of particular importance in 
ongoing peace-building efforts. The classroom offers the potential to break intergenerational cycles of violence by protecting and empowering children and youth. ${ }^{6}$ In Côte d'Ivoire, $61 \%$ of school-age children believe school can prepare students to manage conflicts without violence, and $73 \%$ believe that, in general, education contributes to people living together in peace. ${ }^{7}$ Yet, despite school's peacebuilding potential, UNICEF estimates that $78 \%$ of Ivorian school children have experienced at least one episode of verbal or physical abuse, with $63 \%$ of students reporting physical abuse by a teacher. ${ }^{8}$

Despite the clear need, few interventions to reduce violence from teachers to students have been evaluated using a randomised controlled trial (RCT) design. Exceptions include: the Good School Toolkit, Uganda, a complex whole school intervention implemented over 18 months; ${ }^{9}$ the 2-year, 130 session Right to Play Intervention, trialled in Grade 6 students in Pakistan ${ }^{10}$ as well as two interventions focused on teachers-the Interaction Competencies with Children for Teachers, trialled in Tanzania, ${ }^{11}$ and the Irie Classroom Toolbox, trialled in Jamaica. $^{12}{ }^{13}$ There are also several protocols registered for trials underway in Uganda and Tanzania. ${ }^{14} 15$

This mixed-methods paper contributes to the limited literature on what works to reduce violence against children at school. We report on formative research conducted on the promising intervention 'Apprendre en paix et éduquer sans violence (APEV)' ('Learn in peace and educate without violence'), a brief intervention to reduce teacher violence perpetration and promote peace-building, which was designed by Graines de Paix, an international non-governmental organisation. Our aim was to document the intervention theory of change and gather preliminary evidence on whether the intervention was acceptable to teachers and affected change in intermediate outcomes.

Côte d'Ivoire is a West African country with a long history of migration and more than 60 ethnolinguistic groups. ${ }^{16}$ After independence from France in 1960, Cote d'Ivoire saw several decades of economic growth under President Félix Houphouët-Boigny until his death in 1993. This was followed by two coup d'état's 1999 and 2002, at which time the country was divided into two. This violent military-political crisis resulted in conflict in most areas of the country, which lasted until the end of the postelectoral crisis in 2011. The 2002-2011 crisis left a lasting mark on Ivoirian politics and the violence had long-lasting consequences that were especially severe in the western and north-western regions.

After the crisis, the government collaborated with local and international partners to address the underlying causes of the conflict and promote peacebuilding. In the aftermath of the postelectoral conflict, the government created the Dialogue, Truth and Reconciliation Commission to investigate human rights violations during the years of crisis and recommend strategies for peace consolidation. However, the report of this Commission remains unpublished. The Ministry of Education undertook numerous initiatives, including curriculum revision to integrate peacebuilding activities into the national education programme, a 2009 ministerial decree on the Prohibition of Physical Punishment, a 2012 National Child Protection Policy and expanded professional development opportunities for teachers to educate them to a culture of peace. ${ }^{17}$

APEV is a brief educational and behavioural intervention, which has been developed in close collaboration with the Ministry of Education (hereafter referred to as the Ministry) and is delivered by Ministry personnel. It has been refined iteratively over a period of 6 years in Cote d'Ivoire.

Teacher-counsellors, who are responsible for ongoing teacher training in the Ministry, are trained by Graines de Paix staff to provide the intervention to groups of individual teachers. The teacher-counsellors select two teachers from each school in their area and conduct 2-day trainings with groups of about 20 teachers. Training aims to increase knowledge, motivation and skills to reduce use of physical violence and improve pedagogical techniques. Teacher-counsellors conduct two in-class observations and give feedback to each teacher individually between two and 4 months post-training. APEV is further described in figure $1 .^{18}$

\section{METHODS}

We conducted a mixed-methods study to articulate an initial Theory of Change and explore mechanisms of change among teachers.

\section{Theory of Change}

Theory of Change uses small group activities to articulate the goals, assumptions and perceived mechanisms of positive change. It is a collaborative method aimed at producing a collective consensus of the idea of social change embedded within an intervention. ${ }^{19}$ In March 2017, we hosted a 1-day workshop in Abidjan, with 18 participants including intervention staff, teachers, teacher-counsellors and Ministry of Education members already familiar with the intervention. They identified desired impacts and outcomes, focusing on initial changes within teachers. We then hosted a second workshop in Man, where the intervention was about to be implemented. This workshop included 14 stakeholders who were not yet familiar with the intervention, to add local and context-specific expertise. A member of Graines de Paix explained the intervention and presented the outline of desired outcomes developed in Abidjan. The 14 participants discussed the intended impact in terms of relevance for the region and identified the preconditions they thought were important for each outcome. The results were then arranged into a flowchart.

\section{Quantitative surveys}

Surveys were administered to teachers participating in the intervention to explore change over time in three of the 
Material and content

- A training kit includes a training manual and activities booklet on peace promotion to use with students. Teachers use the activities booklets in their classrooms in order to help students to learn and practice psychosocial skills and improve classroom dynamics. Activities focus on dialogue, conflict resolution, empathy, critical thinking, decision-making, compassion and proactivity.

\section{Procedures}

APEV consists of:

- A four-day training workshop for 20 teacher counsellors to gain skills and motivation on nonviolence classroom techniques and prepare them to become teacher trainers.

- A two-day group training workshop to gain skills and motivation on non-violent classroom management techniques. Workshops use role-plays, experiential activities and reflecting exercises to encourage active participation from teachers.

- Two in-class assessments three and six months following training.

- Face-to-face personalised feedback following each in-class assessment

\section{Who provided}

APEV uses a cascade model of Training of Trainers, with existing Ministry of Education personnel. Graines de Paix staff train Training Experts on the APEV intervention. Training Experts are Ministry supervisors with extensive background in childhood education and peace mediation. Training Experts then train Teacher-counsellors who are responsible for ongoing teacher training in schools. In this instance since the intervention was happening in only one region, GdP personnel provided the teachercounsellor training. Teacher-counsellors in a given region are selected by the Ministry to deliver the intervention to groups of individual teachers. Teacher-counsellors recommend teachers whom they deem may have an impact on their peers and therefore more likely to contribute to change.

\section{How}

The training workshop includes of two full days of activities for a group of approximately 20 teachers. Training is delivered face to face although ad hoc support by telephone can be provided depending on the needs of the teacher. Initial activities are supplemented with two in-class assessments of teachers three and six months following training.

\section{Where}

Teachers come from several different schools to a centrally located school in order to participate in training. Follow up assessments and feedback are provided at their school.

\section{When and how much}

After the initial two-day training, teacher-counsellors perform an assessment three and six months following initial training of the intervention. Teacher-counsellors are also available in schools and by telephone for ad hoc support as requested by the teachers. The training kit contains sixteen classroom activities.

\section{Tailoring, modifications, fidelity}

Five years after the first delivery of the intervention, APEV has undergone slight modifications to its delivery model (using teacher counsellors instead of teachers as trainers) and content changes. Graines de Paix conducts periodic monitoring and evaluation exercises to track the implementation, quality, and effects of the intervention.

Figure 1 'Apprendre en paix et éduquer SANS violence' (APEV), or 'Learn in peace, educate without violence' by Graines de Paix.

eight intermediate Theory of Change outcome measures, which lent themselves to quantitative measurement. Surveys were administered immediately prior to the first training day of the intervention (pretraining survey); at the end of the first day of training (mid-training survey) and 4 months post-training, after the teachers had been implementing classroom strategies and had completed one on one formative evaluations ( 4 months post-training survey). These were completed in February to June 2018. Teachers self-completed surveys on tablet computers.

\section{Measures}

Awareness of the consequences of violence: questions were developed with Graines de Paix (GdP) personnel and tested specifically for this study. Teacher self-efficacy in applying positive classroom management methods: items were drawn from the Norwegian Teacher SelfEfficacy Scale. ${ }^{20}$ Teacher and parent acceptance of physical discipline in school: items were drawn from our previous work in Uganda. ${ }^{21}$ Questions were adapted and refined by the research team and Graines de Paix staff and then cognitively tested and further refined with teachers. For some measures, complete sets of questions were then pretested in groups of 10-25 teachers. We chose to measure the constructs that lent themselves to quantitative measurement.

To generate measures for use in analyses, questions from the pretraining survey were subjected to principal components analyses to determine the number of factors to extract per measure. Exploratory factor analyses were then conducted using oblique (promax) rotation and the 
iterative principle factor estimation method. The internal consistency of the measures generated was calculated using Cronbach's alpha. ${ }^{22}$

This process yielded: an 8-item measure assessing teachers' awareness of the consequences of violence (Cronbach's alpha: 0.81), a 10-item measure assessing teacher self-efficacy in the classroom (Cronbach's alpha: 0.73 ), a 6-item measure assessing teachers' acceptance of physical discipline practices in school (Cronbach's alpha: 0.90 ) and a 6-item measure assessing parents' acceptance of physical discipline practices in school, based on teacher report (Cronbach's alpha: 0.96) (table 1). Scores were assigned to each response option, and mean scores and SD were calculated.

\section{Analyses}

We obtained summary statistics for the outcomes at each time point. Given the presence of missing data, multiple imputation ${ }^{23}$ was used. Assuming that data were missing completely at random, 10 imputations were generated for each outcome, following the Markov Chain Monte Carlo method. This method assumes a joint multivariable normal distribution for variables in the imputation model. ${ }^{24}$ We imputed values for $0.7 \%$ of data at preintervention, $1.9 \%$ at postintervention and $18.4 \%$ at 4 months postintervention.

Random intercept linear mixed-effects models with an unstructured correlation structure were built, controlling for the teacher's age, sex, marital status and reported number of children living in the home. For each outcome, results were combined across the 10 imputed data sets. Changes in the outcomes over time were assessed by examining the mean outcome mid training and 4 months post-training compared with pretraining. Mean differences, 95\% CIs and $\mathrm{p}$ values from Wald tests were derived. We conducted a sensitivity analysis to investigate the potential influence of missingness and found results from a complete-case analysis to be similar to those produced by multiple imputations.

\section{Qualitative methods}

We conducted 19 in-depth interviews (IDIs) and three focus group discussions (FGDs) with teachers and teachercounsellors. Ten IDI (all teachers) were conducted after the initial training, and nine $(n=7$ with teachers and $\mathrm{n}=2$ with teacher-counsellors) were conducted 7 months post-training. All FGDs were conducted after the posttraining survey $(\mathrm{n}=2$ with teachers and $\mathrm{n}=1$ with teachercounsellors). Teachers participating in these activities had all completed survey data collection. Some teachers were participated in both IDIs and FGDs.

Interviewers posed exploratory and open-ended questions about the acceptability of the intervention, their perceived need for such an intervention and changes resulting from participation in the intervention. The open-ended nature of these interviews encouraged teacher participation and led to formative information on the broader context of corporal punishment and violence in schools in Côte d'Ivoire. Interviews were conducted in French.

Travel expenses were compensated, but no financial incentive was provided. The first round of IDIs was recorded with detailed written notes, specifying where a response was summarised and where it was quoted verbatim. The second round of IDIs was recorded and fully transcribed. The team observed non-verbal signals such as body language, pauses, and tone of voice.

Data analysis was conducted using transcripts in French. The data were manually coded into a basic framework analysis, corresponding to the Theory of Change intermediate outcomes. ${ }^{25}$ We also allowed themes beyond the initial coding categories to emerge to identify unintended consequences and other important information. Final quotes and themes were translated to English.

\section{Informed consent and child protection}

Before each survey, interview (IDI) and/or FGD, every participant was given two copies of the information sheet and consent form, one of which they signed and handed over to the research team. Information sheets were either read out loud by the researchers or read by the participant his/herself. Participants were invited to ask any questions to the research team at any time prior, during and after the research process. Teachers were notified in consent forms that disclosure of any acts of serious violence against students would necessitate a referral to child protection services. Types of acts that would necessitate referral in the Ivorian context were agreed in advance of the data collection by the team and the Centre Sociale, which is mandated with child protection in Cote d'Ivoire and approved by London School of Hygiene and Tropical Medicine and Centre Nationale d'Ethique de la Recherche ethics committees. For the survey data, we conducted daily data checks to identify teachers who needed to be referred. Any disclosures in IDIs or FGDs were monitored by the research team. Two referrals were made to a local child protection agency based on survey responses by teachers.

\section{RESULTS}

\section{Theory of Change}

The Theory of Change is summarised in figure 2. Participants identified eight intermediate outcomes in teachers: (1) increased awareness of consequences of violence in children, (2) increased motivation to learn and use nonviolent discipline, (3) increased knowledge of non-violent discipline and peace activities, (4) increased application of non-violence methods of discipline and peace activities in class, (5) improved classroom dynamics, (6) decreased acceptance of violence use, (7) increased confidence in and motivation to apply techniques and (8) teachers use of peace techniques is positively reinforced as a result of personalised feedback sessions.

Participants also expected that training a selection of teachers from various schools would influence other 
Table 1 Description of pre, mid and 4 months post-training measures

\begin{tabular}{|c|c|c|c|}
\hline Measure & Questionnaire items & $\begin{array}{l}\text { Response options } \\
\text { for each item }\end{array}$ & Coding \\
\hline $\begin{array}{l}\text { Awareness of the } \\
\text { consequence of } \\
\text { violence }\end{array}$ & $\begin{array}{l}\text { Some students who experience violence at school } \\
\text { can be quieter than others; } \\
\text { Some students who undergo violence at school find } \\
\text { it hard to concentrate in class than others; } \\
\text { Students who undergo violence at school are more } \\
\text { likely to be absent from school; } \\
\text { Experiencing violence makes students less likely to } \\
\text { participate properly in class; } \\
\text { Some students who experience violence in class } \\
\text { are more likely to bully or be violent towards other } \\
\text { students; } \\
\text { Students who experience violence are more likely to } \\
\text { feel anxious, afraid and sad; } \\
\text { Students who experience violence at school are } \\
\text { less likely to perform well in school; } \\
\text { Students who experience violence at school are } \\
\text { less likely to behave correctly and follow school } \\
\text { rules. }\end{array}$ & $\begin{array}{l}\text { True } \\
\text { Not sure } \\
\text { False }\end{array}$ & $\begin{array}{l}\text { Scores range from } 0 \text { (low) } \\
\text { to } 16 \text { (high). }\end{array}$ \\
\hline $\begin{array}{l}\text { Self-efficacy in } \\
\text { applying positive } \\
\text { classroom } \\
\text { management } \\
\text { methods }\end{array}$ & $\begin{array}{l}\text { In class, I feel I can... } \\
\text {...motivate students who show low interest in } \\
\text { schoolwork; } \\
\text {...involve students in the development of classroom } \\
\text { rules and consequences; } \\
\text {...make sure all students understand expectations } \\
\text { on classroom behaviour; } \\
\text {....communicate and provide encouragement for } \\
\text { students to have good conduct; } \\
\text {...get students with behavioural problems to } \\
\text { respect classroom rules; } \\
\text {...maintain active class participation even with large } \\
\text { class sizes; } \\
\text {...maintain discipline in any class or group of } \\
\text { students without using verbal or physical violence; } \\
\text {...help even the most aggressive students to follow } \\
\text { classroom rules; } \\
\text {...find peaceful solutions to conflicts in the class; } \\
\text {...maintain discipline even with large class sizes } \\
\text { without shouting. }\end{array}$ & $\begin{array}{l}\text { All of the time } \\
\text { Most of the time } \\
\text { Sometimes } \\
\text { Never }\end{array}$ & $\begin{array}{l}\text { Scores range from } 0 \text { (low) } \\
\text { to } 30 \text { (high). }\end{array}$ \\
\hline $\begin{array}{l}\text { Acceptance of } \\
\text { physical discipline } \\
\text { in school }\end{array}$ & $\begin{array}{l}\text { Physical discipline of students by teachers is } \\
\text { normal. } \\
\text { Sometimes teachers must hit students to make } \\
\text { them listen. } \\
\text { Students who misbehave should be physically } \\
\text { disciplined. } \\
\text { Sometimes teachers must hit students to make } \\
\text { them learn. } \\
\text { Sometimes physically disciplining students is the } \\
\text { only way to make them respect you. } \\
\text { It is OK to physically discipline children when they } \\
\text { misbehave. }\end{array}$ & $\begin{array}{l}\text { Strongly agree } \\
\text { Agree } \\
\text { Disagree } \\
\text { Strongly disagree }\end{array}$ & $\begin{array}{l}\text { Scores range from } 0 \text { (low) } \\
\text { to } 18 \text { (high). }\end{array}$ \\
\hline
\end{tabular}


Table 1 Continued

\begin{tabular}{|c|c|c|c|}
\hline Measure & Questionnaire items & $\begin{array}{l}\text { Response options } \\
\text { for each item }\end{array}$ & Coding \\
\hline $\begin{array}{l}\text { Parent acceptance } \\
\text { of physical } \\
\text { discipline in school }\end{array}$ & $\begin{array}{l}\text { Parents who send their children to your school believe } \\
\text { that... } \\
\text { Sometimes physically disciplining children is the } \\
\text { only way to make them respect you. } \\
\text { Sometimes teachers must hit students to make } \\
\text { them listen. } \\
\text { Students who misbehave should be physically } \\
\text { disciplined. } \\
\text { Sometimes teachers must hit students to make } \\
\text { them learn. } \\
\text { Sometimes parents must hit students to make them } \\
\text { listen. } \\
\text { Sometimes parents must hit students to make them } \\
\text { learn. }\end{array}$ & $\begin{array}{l}\text { Strongly agree } \\
\text { Agree } \\
\text { Disagree } \\
\text { Strongly disagree }\end{array}$ & $\begin{array}{l}\text { Scores range from } 0 \text { (low) } \\
\text { to } 18 \text { (high). }\end{array}$ \\
\hline
\end{tabular}

teachers and lead to an overall reduction of teacher violence against students in whole schools.

\section{Quantitative results}

In total, 160 teachers completed the pretraining questionnaire; 157 completed the mid-training questionnaire and $137(86 \%)$ of these completed the 4-month posttraining questionnaires. Of the 160 teachers, $62 \%$ were men and the mean age was 37 years. Most (74\%) were in a relationship and nearly all $(92 \%)$ were caring for at least one child. Most of the samples were teachers (74\%) and over half $(58 \%)$ had been in their current job for 6 or more years.

The results (table 2) showed no change in awareness of consequences of violence post-training, (mean scores

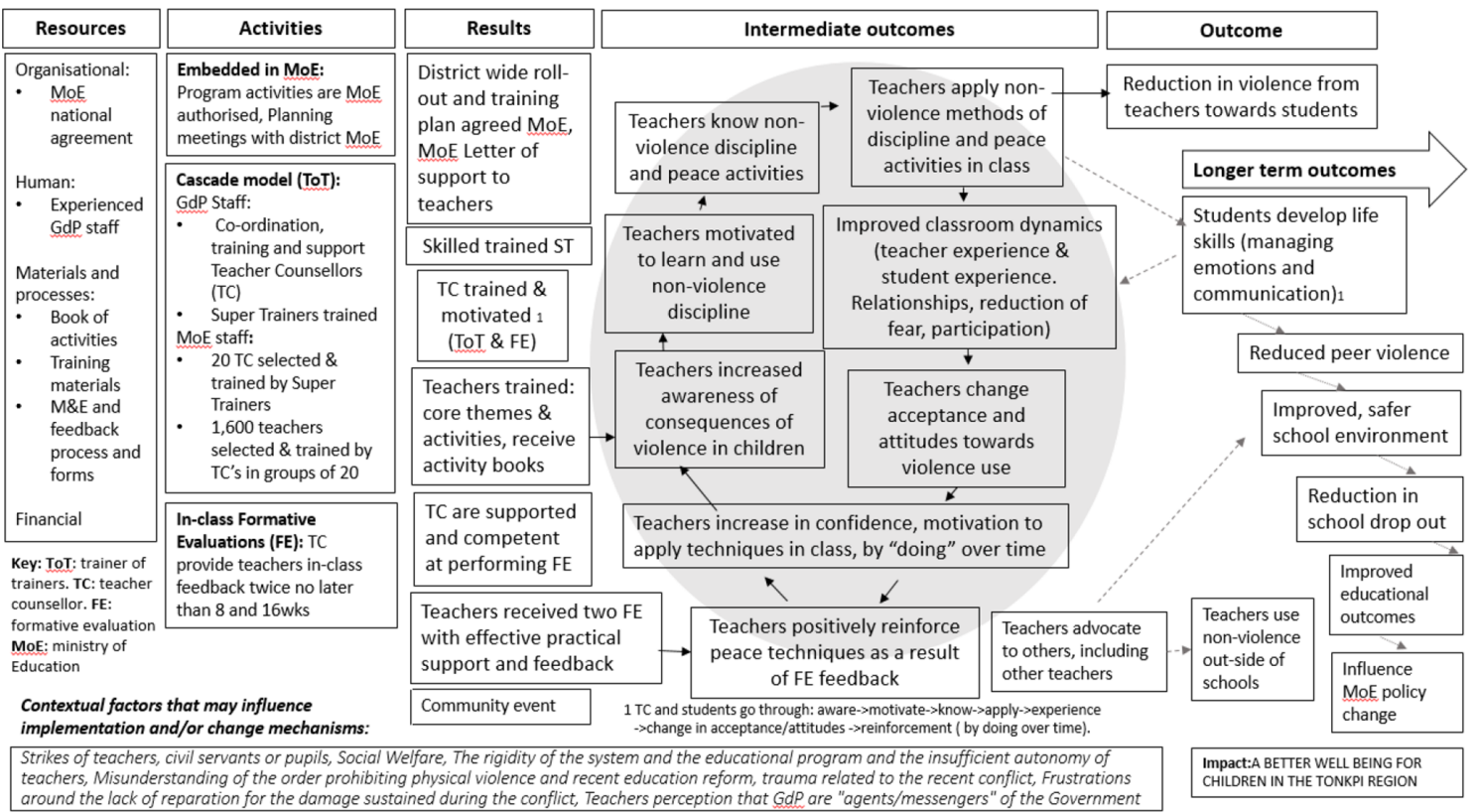

Initial Theory of Change:

- The intervention is theorised to increase both teachers' awareness of the consequences of violence in children and their motivation to learn and apply non-violent discipline methods and peace activities in the classroom.

- Teachers' motivation and capacity to apply techniques and activities are reinforced by individual in-class formative evaluations that encourage teachers to "learn by doing".

- Teachers application of techniques and activities over time are hypothesised to bring about positive change to classroom dynamics and teachers' own experience and observations of these changes are expected to further reinforce intervention themes and motivate teachers.

- This hypothesised reinforcement of teachers' capacities to bring about positive change is expected to lead to a reduction in teachers' acceptance and use of violence towards students in and out classroom.

Figure 2 Theory of Change flowchart model. Gdp, Graines de Paix; MoE, Ministry of Education; ToT, Training of Trainers. 
Table 2 Intermediate outcomes and changes in intermediate outcomes mid-post, and 4 months post compared with pretraining among teachers, using multiple imputations*

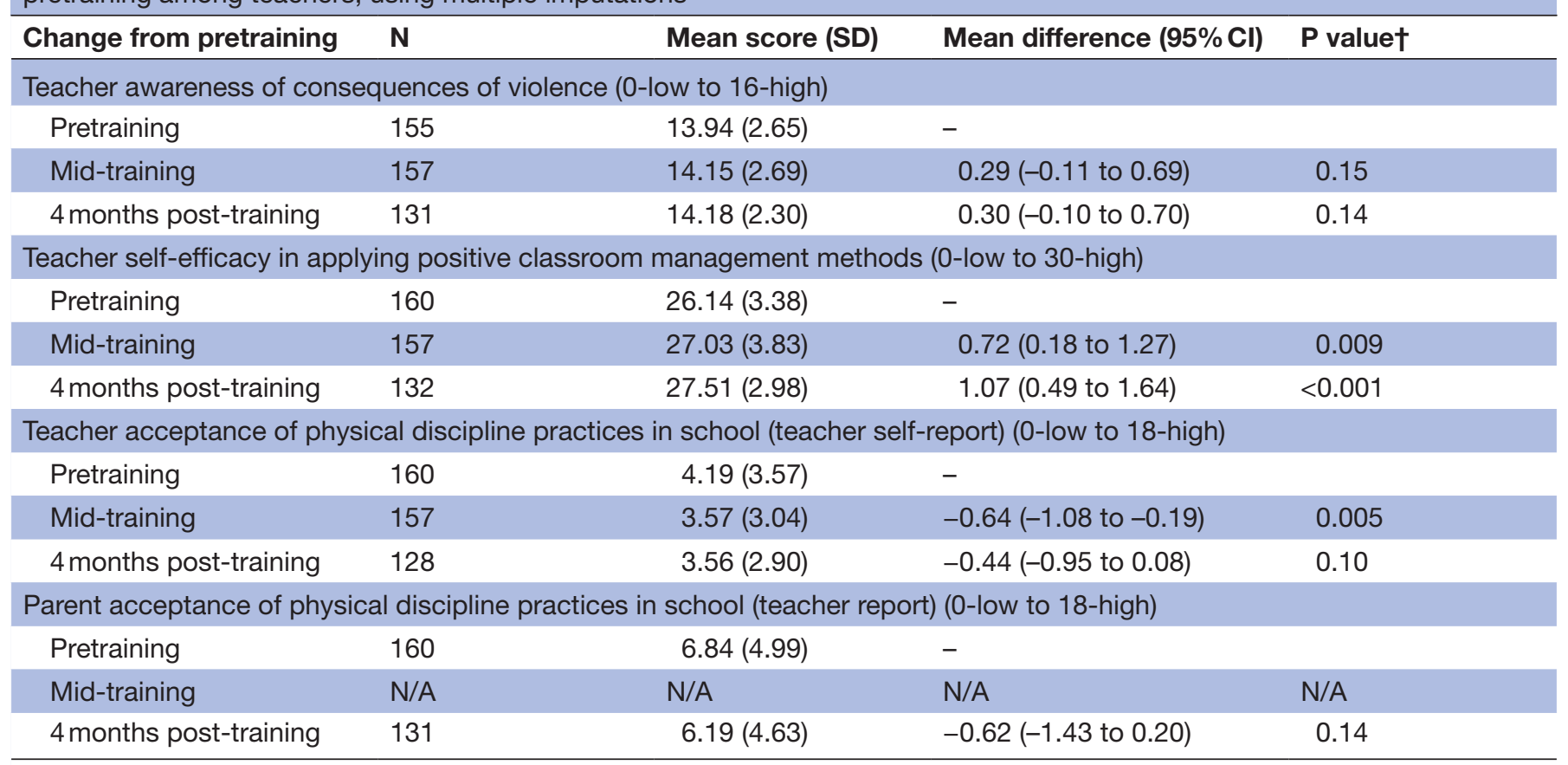

Surveys completed by 160 teachers at pretraining, 157 teachers at mid-training, and 137 teachers at 4 months post-training.

${ }^{*}$ Assessed using random intercept linear mixed-effects models with an unstructured correlation structure, controlling for age, sex, marital status and number of children living in the home. Ten imputations were generated per model.

†P values are Wald tests.

were 13.94, 14.15 and 14.18 at pre, mid and 4-month post-training, respectively; score range: 0 -low to 16-high). Self-efficacy was high before the intervention (mean: 26.11; score range: 0-low to 30-high) but was higher midtraining (mean: 27.03; mean difference with pretraining: $0.72(0.18$ to 1.27$) ; \mathrm{p}<0.01)$ and increased again 4 months post-training (mean 27.51; mean difference with preintervention: 1.07 (0.49 to 1.64$)$; $\mathrm{p}<0.001)$. This increase supports two Theory of Change intermediate outcomes: (2) teachers motivated to learn and use non-violent discipline and (7) teachers increase their confidence and motivation to apply techniques. Lower acceptance of physical discipline practices in schools was reported mid-training (mean: 3.57; score range: 0-low to 18-high) compared with pretraining (mean: 4.20) (mean difference -0.64 $(-1.08$ to -0.19$) ; \mathrm{p}<0.01)$. However, this difference did not persist at 4 months post-training (mean difference $-0.44(-0.95$ to 0.08$) ; p=0.10)$. The evidence of change from pre-training to mid-training supports the Theory of Change intermediate outcome (6), that teachers change acceptance and attitudes towards violence use. No change was observed in teachers' report of parent acceptance of physical discipline practices in school at 4 months posttraining versus pretraining (mean difference: -0.62 $(-1.43$ to 0.20$) ; \mathrm{p}=0.14)$.

\section{Qualitative results}

Interviews were conducted with 17 teachers and 2 teacher-counsellors: 13 interviewees were men and 6 were women. Ages ranged from 26 to 59 years. A total of six male and five female teachers and teacher-counsellors aged 29-59 years participated in the FGDs. IDI and FGD findings are summarised and illustrated with example quotes, in three sections: context, theory of change, new emerging themes and unintended consequences.

Context: teachers' views on physical discipline and alternative methods

Teachers demonstrated strong existing knowledge that physical discipline was no longer permitted in schools.

The minister herself says it. Non-violence with children. We must be gentle-female teacher, IDI, September 2018.

However, many teachers also expressed the view that 'lighter' corporal punishment methods, such as the chicote (switch), were an effective way to ensure students learn:

Regarding the chicote; an African child, to bring him/her into line, a bit of chicote is needed. But the European child, he/she, through dialogue, will bring himself/herself into line. So these kinds of questions, we Africans, the West has to try to understand our realities. A child's education in Africa must inevitably include a bit of chicote-male teacher, IDI, September 2018. 
Several teachers were of the view that 'African' children would not respond to alternative methods of discipline. Many teachers deemed positive sanctions, such as those suggested by the intervention, too lax:

It is a little complicated with the pupils at this school. We are helpless because the ban on chicote means that we have very few methods to discipline pupils. We talk a lot more to keep them quiet but that does not work because the children do not respect usmale teacher, IDI, February 2018.

\section{Theory of change}

Findings in relation to the Theory of Change are summarised in table 3 . We found broadly that qualitative evidence supported the mechanisms outlined in the Theory of Change, with the exceptions of awareness of the consequences of violence and improved classroom dynamics where no changes/improvements were noted.

New emerging themes: self-regulation and changing behaviour Teachers discussed the self-restraint and change of behaviour and long-standing habits necessary for them to implement new peace techniques. They discussed how the implementation of new peaceful discipline techniques required self-control. For some, this was difficult:

(...) They make you not even mastering yourself. You do not manage to control yourself, you have to go out because always the habit is there-female teacher, FGD, September 2018.

However, others were successful in overcoming that struggle:

(...) it works but it is something you have to do with, we get on with it because we ourselves ... we often control ourselves. When we lead another activity, we remember that hum, careful. Careful, you've just undergone trainings there, well we're told to ... well often you have to restrain yourself ... Frankly. Otherwise it's not easy—female teacher, FGD, September 2018.

Others discussed that changing was a lengthy process:

(...) we try. With Graines de Paix which has just arrived. As it has just happened, we cannot immediately change the mentality of people. I think it will come over time-female teacher, IDI, September 2018.

\section{Unintended consequences}

Some teachers also discussed unintended consequences of some of the intervention activities. Individual teachers' implementation of techniques from the intervention followed an iterative process of trial and error. One teacher noted that the positive sanction of dancing and singing had unintended consequences, as some students arrived late intentionally, so as to provoke this sanction:

But when we talk about singing, dancing, they like it so much! They like it so much, so they are happy (male teacher, IDI, September 2018).
He was not the only teacher with this specific problem, as another reported:

Well I think that these techniques for the moment are difficult to apply. Because you ask the child to sing, he sings eh! I have 70 students, if there are at least 10 who come late, the 10 will sing. Not only does it delay the course and then they will continue to come [late] because you call a child you tell him "he must dance", he dances, he sings-male teacher, IDI, September 2018.

While the positive sanction generated a positive response from the students, it left teachers uncertain about whether the intended effect had been achieved.

\section{DISCUSSION}

We found both qualitative and quantitative evidence for changes in many of teachers' intermediate outcomes as a result of exposure to the intervention, in accordance with the intervention Theory of Change. Although teachers' accounts largely confirmed the Theory of Change, our findings also highlighted that high awareness of the consequences of violence was already present and did not, therefore, seem to be an important part of the pathway to change. Progress between components of the change pathways also appeared non-linear, which was expected. Our findings further highlighted that teachers were actively engaged in a process of selfregulation and behavioural change to form new habits related to discipline techniques, something which had not been explicitly articulated as part of the Theory of Change. Graines de Paix is considering whether content around self-control should be added to the training, to assist teachers. Some unintended consequences of specific intervention activities were highlighted. However, in general, teachers felt Ministry policies on non-violent discipline were made at a central level and imposed on them, and perceived the intervention as useful because it actually provided methods for non-violent discipline and peace-building. Our results suggest that APEV warrants further investigation in a RCT to test effectiveness in reducing physical violence from teachers to students.

\section{Comparison to other literature}

Relatively few similar studies have been conducted. However, our results are consistent with process evaluation and qualitative findings from the Good Schools Study, which showed that the Good School Toolkit reduced physical violence from teachers to students by $40 \%$ in Uganda. In that study, we found that teachers also discussed the efficacy of the intervention in a mixed and variable way, and that there was a general perception that the intervention worked for some students, some of the time, but was not successful for everyone, all the time. ${ }^{26}$ Similarly, some of our process evaluation findings in that study 
Table 3 Qualitative findings in relation to the Theory of Change

\section{Theory of Change \\ Summary of qualitative findings}

(1) Teachers increased awareness of consequences of violence in children

Teachers discussed a range of consequences of physical violence before and after the intervention. Much discussion centred on school drop out as a consequence, but teachers were divided as to whether this was an effect of violence or not. We interpret these findings as consistent with the quantitative results, which showed high levels of awareness of the consequences of violence and no increase over time.

\section{Illustrative quotes}

Before, our teachers used the chicote a lot, now called violence. It was a kind of motivation and an awareness to improve oneself always and that had its share of consequences. Female teacher, IDI, February 2018

The Graines de Paix training that you bring us! I really am satisfied. Why do I say that I am satisfied? This is because, with the practice of non-violence in school, we see that the schooling rate has increased. That's a satisfaction. Male teacher, FGD, September 2018. despite the fact that there is no "chicote", there are children who drop out of schools. It is not necessarily the "chicote". Male teacher, FGD, September 2018.

(2) Teachers motivated to learn Teachers expressed motivation to learn and use non-violent discipline non-violent disciplinary tactics, although this varied over time. As one teacher explained, several months after her training, the motivation generated by the intervention was challenged during attempts to implement new techniques.

I am very happy first. I learn notions of nonviolence. Before we were told not to use the chicotte but no one came to train us. Now we see that it is not a game. Now it must truly be applied. Male teacher, IDI September 2018

When you leave the training, you are very excited to start your first day, until the moment you arrive next to the still desperate children; already at the flag [morning assembly] you are frankly discouraged, and then even you start to be depressed... Female teacher, IDI, September 2018

(3) Teachers know non-violent discipline and peace activities discipline and peace activities in class
There was an improvement in knowledge of non-violent disciplinary techniques, which teachers welcomed in order to fulfil Ministry requirements. Four months post-intervention, after the individualised reinforcement training, the interviewees spoke about classroom techniques with more familiarity. The specific activities they mentioned were classroom charters, songs and dances, and verbal encouragement towards students.

There was clear evidence that teachers had applied non-violent disciplinary techniques, with most teachers mentioning these at the interviews 4 months post-training. After trialling the non-violent methods, interviewees expressed fewer doubts about the efficacy of positive sanctions. However, there were still mixed views on the effectiveness of techniques over time.
After 3 years in the field, we are told that there is the Skills-Based Approach (SBA) and we are given the documents, without really training ourselves and inviting us to apply them. In spite of all this, the students are constantly not doing well. With the training of Graines de Paix and other trainings (online), I have acquired something additional. That forged my mind at the level of disciplinary actions. Already, I have drawn up a charter with the contribution of my pupils. This class charter established by the pupils began to be applied. Male teacher, IDI, February 2018

Myself, in my classroom, there is the charter. If a child chats in class, we ask the other pupils "do we chat in class? They say "no". The child already is a little embarrassed. He keeps quiet. Male teacher, IDI, September 2018

I cannot lie, the first weeks it was ok, it worked, but after the kids started their behaviour again! After, that's what I mean, they like novelty, but after they resume their behaviour. Female teacher, FGD, September 2018 
Table 3 Continued

Theory of Change

(5) Improved classroom dynamics

(6) Teachers change acceptance and attitudes towards violence use
Summary of qualitative findings

Teachers generally did not perceive that the intervention had led to improved classroom dynamics, in the form of relationships between students and teachers. Teachers often commented that students showed less 'fear' towards them, but this was often not framed in a positive way by teachers themselves. Several teachers still questioned the efficacy of a peaceful approach towards students who made frequent mistakes; they associated it with 'lax' teaching and low expectations.

Teachers acknowledged that changing the classroom dynamic is a gradual process and expressed a strong conviction that a positive outcome would be observed in the long term.

Many teachers spoke more assuredly about the benefits of non-violence, including increased attendance. However, September 2018

this view was not universal, and some argued that African children are not responsive to non-violent techniques. We interpret these results as broadly consistent with the quantitative results, which show small but statistically significant decreases in teacher acceptance of physical discipline techniques over time.

(7) Teachers increase Success in implementing some methods confidence, motivation to apply from the intervention led to increased techniques interest in learning others. In the postintervention interviews, teachers also began to call for further intervention and action targeting parents, community members and teachers, rather than simply observing the 'difficulty' of implementing non-violence in classrooms when it may not be practised in streets and homes. This suggests that teachers' increased confidence with the content of the intervention over time.

(8) Teachers positively reinforce Teachers were unequivocally positive peace techniques as a result of about the value of participating in the formative evaluations Graines de Paix intervention. They saw it as adding distinct value to their professional development, going beyond the existing Ministry of Education programmes. Non-judgmental dialogue between educators was one of the most consistently praised aspects of the intervention, and feedback in the school environment where teachers worked.

\section{Illustrative quotes}

Nowadays, with nonviolent techniques, children no longer study. There is no more pressure. Because they know that, whether they study or not they will progress to the next grade. Studying therefore is none of the child's business. Male teacher, FGD, September 2018

Because of the charter of the classroom, the child knows that by coming late, he will have a sanction. To avoid having a sanction, the child comes on time. So it worked for me, it worked! Often children fight against each other in the classroom. After the charter was applied everything stopped and then there was no violence until the end of the year. Male teacher, IDI, September 2018

Graines de Paix, as you said, it's a seed. Little by little. Otherwise, it will take shape, for sure!" Male teacher, IDI, September 2018

I think violence does not solve a problem. It only aggravates the problem. Female teacher, IDI,

... the [exam] success rate is good. The success rate is good because we said, we do not do violence to children anymore. So people are comfortable now to come to school. Male teacher, FGD, September 2018

...it [violence] must be said that in Africa, this is how to master a child. Female teacher, IDI, September 2018

'I tried singing and dancing this year. Maybe next year, I'Il look at other sanctions I'm going to use'. With teachers alone it's difficult. The child has another education at home, when he arrives at school there is another education... we also have to talk to our children to make it easier for the teachers because they alone cannot anymore. They alone cannot educate them. Education there depends on us all. Parents and teachers ... That's it. Female teacher, FGD, September 2018

the best training is in our immediate environment. This is the school, for you to see; the (Graines de Paix) trainers are confronted with our realities'

(Male teacher, FGD, September 2018). pointed to quantitatively small changes in intermediate outcomes, ${ }^{27}$ and yet the intervention had a large effect.
Our qualitative findings also highlight a discourse, which is prevalent in child protection work globally, where teachers perceived ideas of alternative 
discipline as 'non-African' and not effective or appropriate for 'African children'. While this is a discourse that may shift over the course of exposure of intervention, it highlights a central challenge for successful implementation of interventions in this area. Others designing interventions, which are counter to prevailing norms around child discipline, must be mindful of how they engage with different communities at the outset, in order to facilitate uptake of new ideas. Similar to the Good Schools Study, teachers reported scepticism but did test out new intervention techniques in their classrooms. Over time and repeated implementation, many teachers began to see changes in student behaviour and, therefore became convinced of the efficacy of the techniques. ${ }^{26}$

\section{Experiences in relation to Ivorian context}

Teachers' accounts of experiences with the intervention were situated in the broader context of education provision and Ivorian history and politics. School enrolment has increased at all levels; the school-age population rose from 8.7 to 12.7 million between 2000 and 2012 and is expected to grow to 14.7 million by 2025 . This adds strong demographic pressure on the education system. ${ }^{28}$ Teachers' accounts frequently mentioned the difficulties related to economic conditions, the need for more classrooms, training and support, the deterioration of school infrastructures/facilities and the difficult teaching conditions. Teachers' perceptions of the need for more support may have facilitated their uptake of training provided by Graines de Paix, as suggested by our qualitative findings.

Furthermore, the years of political crisis in Cote d'Ivoire challenged the legitimacy of governance institutions and undermined social cohesion in many regions. In the Tonkpi region, it exacerbated tensions between communities, especially around issues related to the sharing of resources such as land or pastures. ${ }^{29}$ Graines de Paix intentionally framed the programme as a peace intervention to situate it appropriately in this postconflict context.

\section{Strengths and limitations}

Our study was designed to be a formative assessment to determine whether further research on the effectiveness of APEV was warranted. We purposely directed our budget towards work with teachers and aimed to clarify and understand the mechanisms of how the intervention might work. We, thus, did not include direct work with primary school students, who would be the ultimate intended beneficiaries of the intervention. A larger scale evaluation of APEV should measure its main outcomes in students themselves. Further work is needed to understand student experiences of violence in Ivorian primary schools, and how best to measure these. Teachers were notified in consent forms that disclosure of any acts of serious violence against students would necessitate a referral to child protection services, and this may have affected reporting. Based on our experience with adapting, administering and interpreting internationally used measures for teachers in this context, we suggest that context-specific adaptations of violence measures and modes of administration should be piloted for students, as we encountered substantial reluctance to disclose use of some forms of violence by teachers. This is in contrast to our experience in several East African settings ${ }^{930}$ and is further explored and discussed in a separate paper. ${ }^{31}$

Participants for the intervention are in general selected based on their reputations as 'changemakers' within their schools, and it is important to interpret results in light of this. The magnitude of the changes observed quantitatively in teachers' intermediate outcomes was relatively small. This is expected to some extent in a brief and less intensive intervention; however, it could also be that these small changes do not translate into detectable changes in teachers' use of violence. Indeed, correlations between attitudes towards violence and violence behaviour are weak to moderate, meaning that attitude change on its own does not necessarily imply behaviour change or vice versa. Further, larger scale evaluation is needed to establish whether APEV can cause changes in behaviour.

\section{Implications}

Based on the results of this formative research, Graines de Paix has introduced several refinements to APEV. These include: adding content to support teacher's self-regulation, as this emerged from the qualitative research; lengthening the number of training days, as the intervention effects were positive but relatively small in magnitude; adding teacher practice exchange days, so that teachers can collaborate and critically reflect on how to use the programme's tools based on their experiences; adapting in partnership with teachers the techniques that were reported to be difficult to implement; including awareness raising activities with school parents and strengthening the programme's links to the national education system by including school inspectors in trainings and by linking classroom activities directly to the national curriculum.

Given the dearth of rigorously tested intervention models to reduce violence from teachers to students, an RCT of APEV would provide welcome evidence to the field about effective ways to reduce this from of violence. Currently tested models include whole-school approaches and/or those involving multiple actors in a school ${ }^{9} 10$ as well as other examples of teacher-focused programming. ${ }^{12}$ All of these are longer than APEV. There are few brief interventions to reduce violence, but in other fields (eg, changing alcohol use behaviour), brief interventions can be equally effective when compared with longer interventions. ${ }^{32}$ APEV has also been developed in close collaboration with the Ministry of Education and is delivered by Ministry personnel, making it inherently easy to scale. We also note that existing interventions with evidence of efficacy ${ }^{93}$ have not yet been widely implemented on national scales, which may be in part because neither is delivered by Ministries of Education. 


\section{CONCLUSION}

APEV is a promising, brief intervention to reduce violence from teachers to primary school students in Ivorian schools. This intervention should be evaluated for its effectiveness in an RCT.

\section{Author affiliations}

${ }^{1}$ Department of Global Health and Development, London School of Hygiene and Tropical Medicine, London, UK

${ }^{2}$ Université Félix Houphouët-Boigny, Abidjan, Lagunes, Côte d'Ivoire

${ }^{3}$ Bloomburg School of Public Health Johns Hopkins University, Baltimore, Maryland, USA

${ }^{4}$ Graines de Paix, Abidjan, Côte d'Ivoire

${ }^{5}$ Department of Medical Statistics, London School of Hygiene \& Tropical Medicine, London, UK

\section{Twitter Mazeda Hossain @mazedahossain}

Acknowledgements We gratefully acknowledge the participants in our study, for giving up their time and for their valuable insights. We also acknowledge the Graines de Paix office staff in Cote d'Ivoire, for their hosting and facilitation; as well as the Graines de Paix team in Geneva for their willingness to learn.

Contributors KD designed the study, obtained funding and co-drafted the manuscript. MB managed some of the qualitative fieldwork and the 4-month follow-up quantitative survey, analysed some qualitative data and co-drafted the manuscript. KT managed the pretraining and post-training quantitative surveys and some qualitative work; analysed some qualitative data, and co-drafted the manuscript. LK co-designed the study, co-managed the Theory of Change development, and co-managed some qualitative work. FP co-managed the theory of change development and some qualitative work. YABN'D and DGFN'G collected qualitative and quantitative data. KGM analysed quantitative data and co-drafted the manuscript. MD participated in the design of the study, development of the Theory of Change and facilitated the conduct of all qualitative and quantitative fieldwork. CT co-drafted the manuscript. LQ participated in the design of the study and obtained funding. EA, MH, BC and all other authors input and commented critically on the manuscript. KD is guarantor and accepts full responsibility for the work and/or the conduct of the study, had access to the data, and controlled the decision to publish.

Funding Funding for this research was provided by the UBS Optimus Foundation (award/grant number is not applicable) and the Open Road Foundation (award/ grant number is not applicable). KGM was supported by the National Institute of Mental Health of the National Institutes of Health under award number F31MH116821-01A1.

Competing interests $L Q$ and MD were employed by Graines de Paix, which developed the APEV intervention. They were involved in the study design; facilitated independent data collection by LSHTM and Université Félix Houphouët-Boigny; and input into interpretation of findings. Final decisions on design and interpretation rested with $\mathrm{KD}$.

Patient and public involvement Patients and/or the public were not involved in the design, or conduct, or reporting, or dissemination plans of this research.

Patient consent for publication Not applicable.

Ethics approval The study received ethical approval from the London School of Hygiene and Tropical Medicine (LSHTM) (ref 14014 and 14537) and the Centre Nationale d'Ethique de la Recherche (CNER) based in Abidjan.

Provenance and peer review Not commissioned; externally peer reviewed.

Data availability statement No data are available.

Open access This is an open access article distributed in accordance with the Creative Commons Attribution Non Commercial (CC BY-NC 4.0) license, which permits others to distribute, remix, adapt, build upon this work non-commercially, and license their derivative works on different terms, provided the original work is properly cited, appropriate credit is given, any changes made indicated, and the use is non-commercial. See: http://creativecommons.org/licenses/by-nc/4.0/.

\section{ORCID iDs}

Karen Devries http://orcid.org/0000-0001-8935-2181

Mazeda Hossain http://orcid.org/0000-0002-1878-8145

Clare Tanton http://orcid.org/0000-0002-4612-1858
REFERENCES

1 Hillis S, Mercy J, Amobi A, et al. Global prevalence of Past-year violence against children: a systematic review and minimum estimates. Pediatrics 2016;137:e20154079.

2 Devries K, Knight L, Petzold M, et al. Who perpetrates violence against children? A systematic analysis of age-specific and sexspecific data. BMJ Paediatr Open 2018;2:e000180.

3 Norman RE, Byambaa M, De R, et al. The long-term health consequences of child physical abuse, emotional abuse, and neglect: a systematic review and meta-analysis. PLoS Med 2012;9:e1001349.

4 Boden JM, Horwood LJ, Fergusson DM. Exposure to childhood sexual and physical abuse and subsequent educational achievement outcomes. Child Abuse Negl 2007;31:1101-14.

5 Fergusson DM, McLeod GFH, Horwood LJ. Childhood sexual abuse and adult developmental outcomes: findings from a 30-year longitudinal study in New Zealand. Child Abuse Negl 2013;37:664-74.

6 Scott L. The crossroads of child protection and education in peacebuilding. New York, 2013.

7 Vinck P, Pham P, Balthazard M. Now the Kids Are Safe: PopulationBased Survey on Peace and Education in Côte d'Ivoire. MA: UNICEF, Harvard Humanitarian Initiative Cambridge, 2016.

8 MENET-UNICEF. Etude sur le bien-être et la sécurité des élèves dans les écoles de Côte d'/voire. Adidjan, Republique de Côte d'Ivoire: Ministere de l'education nationale et de l'enseignement technique (MENET), Fonds des Nations Unies pout I'Enfance, UNICEF, 2015

9 Devries KM, Knight L, Child JC, et al. The good school toolkit for reducing physical violence from school staff to primary school students: a cluster-randomised controlled trial in Uganda. Lancet Glob Health 2015;3:e378-86.

10 Karmaliani R, McFarlane J, Khuwaja HMA, et al. Right to play's intervention to reduce peer violence among children in public schools in Pakistan: a cluster-randomized controlled trial. Glob Health Action 2020;13:1836604.

11 Nkuba M, Hermenau K, Goessmann K, et al. Reducing violence by teachers using the preventative intervention interaction competencies with children for teachers (ICC-T): a cluster randomized controlled trial at public secondary schools in Tanzania. PLoS One 2018;13:e0201362.

12 Baker-Henningham $\mathrm{H}$, Bowers $\mathrm{M}$, Francis $\mathrm{T}$, et al. The Irie classroom toolbox, a universal violence-prevention teacher-training programme, in Jamaican preschools: a single-blind, cluster-randomised controlled trial. Lancet Glob Health 2021;9:e456-68.

13 Baker-Henningham H, Scott Y, Bowers M, et al. Evaluation of a Violence-Prevention programme with Jamaican primary school teachers: a cluster randomised trial. Int J Environ Res Public Health 2019;16:2797.

14 Devries KM. Preventing violence against children in schools study (PVACS): ClinicalTrials.gov, NCT03745573, 2018. Available: https:// clinicaltrials.gov/ct2/show/NCT03745573?term=devries\&rank=5

15 Ssenyonga J, Hermenau K, Nkuba M, et al. Reducing violence against children by implementing the preventative intervention interaction competencies with children for teachers (ICC-T): study protocol for a cluster randomized controlled trial in southwestern Uganda. Trials 2018;19:435.

16 Akindès F. The Roots of the Military-Political Crises in Côte d'Ivoire. In: Research report, 2004.

17 N'Guessan GKD, Ndjore YAB. Quelle évaluation pour les écoles confessionnelles islamiques intégrées en Côte d'Ivoire? in African educational development issues. Abidjan, 2016.

18 Hoffmann TC, Glasziou PP, Boutron I, et al. Better reporting of interventions: template for intervention description and replication (TIDieR) checklist and guide. BMJ 2014;348:g1687.

19 De Silva MJ, Breuer E, Lee L, et al. Theory of change: a theory-driven approach to enhance the medical Research Council's framework for complex interventions. Trials 2014;15:267.

20 Skaalvik EM, Skaalvik S. Dimensions of teacher self-efficacy and relations with strain factors, perceived collective teacher efficacy, and teacher burnout. J Educ Psychol 2007;99:611-25.

21 Merrill KG, Knight L, Glynn JR, et al. School staff perpetration of physical violence against students in Uganda: a multilevel analysis of risk factors. BMJ Open 2017;7:e015567.

22 Cronbach LJ. Coefficient alpha and the internal structure of tests. Psychometrika 1951;16:297-334.

23 Rubin DB. Multiple imputation for nonresponse in surveys, 1987: 485

24 Schafer J. Analysis of incomplete multivariate data, 1997: 72.

25 Gale NK, Heath G, Cameron E, et al. Using the framework method for the analysis of qualitative data in multi-disciplinary health research. BMC Med Res Methodol 2013;13:117. 
26 Kyegombe N, Namakula S, Mulindwa J, et al. How did the good school toolkit reduce the risk of past week physical violence from teachers to students? qualitative findings on pathways of change in schools in Luwero, Uganda. Soc Sci Med 2017;180:10-19.

27 Knight L, Allen E, Mirembe A, et al. Implementation of the good school toolkit in Uganda: a quantitative process evaluation of a successful violence prevention program. BMC Public Health 2018;18:608.

28 MENET-MESRS. Plan Sectoriel Education/Formation 2016-2025. Abidjan, République de Côte d'Ivoire: Ministère de l'éducation nationale et de l'enseignement technique et de la Formation Professionnelle (MENETFP) ; Ministère de l'Enseignement Supérieur et de la Recherche Scientifique (MESRS), 2017.

29 Pritchard MF. Contesting land rights in a post-conflict environment: Tenure reform and dispute resolution in the centre-West region of Côte d'Ivoire. Land use policy 2016;54:264-75.
30 Lees S, Devries K. Local narratives of sexual and other violence against children and young people in Zanzibar. Cult Health Sex 2018:20:99-112.

31 Merrill KG, Smith SC, Quintero L, et al. Measuring violence perpetration: stability of teachers' self-reports before and after an anti-violence training in Cote d'Ivoire. Child Abuse Negl 2020;109:104687.

32 Kaner EF, Beyer FR, Muirhead C, et al. Effectiveness of brief alcohol interventions in primary care populations. Cochrane Database Syst Rev 2018;2:CD004148.

33 McFarlane J, Karmaliani R, Maqbool Ahmed Khuwaja $\mathrm{H}$, et al. Preventing peer violence against children: methods and baseline data of a cluster randomized controlled trial in Pakistan. Glob Health Sci Pract 2017;5:115-37. 